\title{
As-Grown Domain Structure in Calcium Orthovanadate Crystals
}

\author{
Ekaterina Shishkina ${ }^{1} \mathbb{1}$, Vladimir Yuzhakov ${ }^{1}$, Maksim Nebogatikov ${ }^{1}$, Elena Pelegova ${ }^{1}$, Eduard Linker ${ }^{1}$, \\ Lyudmila Ivleva ${ }^{2}$ and Vladimir Shur $1, *$ (D) \\ 1 School of Natural Sciences and Mathematics, Ural Federal University, 620000 Ekaterinburg, Russia; \\ ekaterina.shishkina@urfu.ru (E.S.); vladimir.yuzhakoff@mail.ru (V.Y.); maxneb@urfu.ru (M.N.); \\ elena.pelegova@urfu.ru (E.P.); eduard.linker@urfu.ru (E.L.) \\ 2 Prokhorov General Physics Institute, Russian Academy of Sciences, 119991 Moscow, Russia; ivleva@lst.gpi.ru \\ * Correspondence: vladimir.shur@urfu.ru; Tel.: +7-343-389-9568
}

check for updates

Citation: Shishkina, E.; Yuzhakov, V.; Nebogatikov, M.; Pelegova, E.; Linker, E.; Ivleva, L.; Shur, V. As-Grown Domain Structure in Calcium Orthovanadate Crystals. Crystals 2021, 11, 1508. https://doi.org/ $10.3390 /$ cryst 11121508

Academic Editor: Ludmila Isaenko

Received: 31 October 2021

Accepted: 30 November 2021

Published: 3 December 2021

Publisher's Note: MDPI stays neutral with regard to jurisdictional claims in published maps and institutional affiliations.

Copyright: (c) 2021 by the authors. Licensee MDPI, Basel, Switzerland. This article is an open access article distributed under the terms and conditions of the Creative Commons Attribution (CC BY) license (https:// creativecommons.org/licenses/by/ $4.0 /)$.

\begin{abstract}
An as-grown domain structure in nominally pure and Mn-doped calcium orthovanadate (CVO) crystals was studied by several methods of domain imaging: optical microscopy, piezoelectric force microscopy, and Cherenkov-type second harmonic generation. The combination of imaging methods provided an opportunity for comprehensive study of the domain structure on the polar surface and in the bulk of the samples. It was shown that, in nominally pure CVO crystals, an irregular 3D maze of rounded domains, with charged walls, essentially tilted from the polar direction, was present. It was proposed that the domain structure was formed just below the phase transition temperature and persisted during subsequent cooling. Such behavior is due to effective bulk screening of the depolarization field and a low value of the pyroelectric field which appears during cooling. The revealed formation of triangular domains and flat fragments of domain walls in Mn-doped CVO was attributed to polarization reversal under the action of the polar component of the pyroelectric field, above the threshold value for domain switching. This fact represents the first observation of the domain switching in CVO crystals.
\end{abstract}

Keywords: domain structure; charged domain walls; domain imaging; second harmonic generation; pyroelectric field

\section{Introduction}

The single crystals of calcium orthovanadate $\left(\mathrm{Ca}_{3}\left(\mathrm{VO}_{4}\right)_{2}\right)(\mathrm{CVO})$ are considered as a laser host material [1]. It has been shown that the high optical damage threshold [2] and nonlinear optical coefficients of $\mathrm{CVO}$ are comparable to those of potassium dihydrophosphate $\left(\mathrm{KH}_{2} \mathrm{PO}_{4}\right)(\mathrm{KDP})$ [3]; therefore, these crystals are potentially useful for frequency conversion of tunable laser sources. CVO possesses the trigonal space group R3c [2], and, being acentric, demonstrates intense second harmonic generation. Recently, nominally pure CVO crystals, and those doped by Mn and rare earth elements (Tm, Ho), have become of special interest due to their potential application as a new active medium for $2 \mu \mathrm{m}$ lasers [4-7].

Ferroelectricity in CVO single crystals was discovered by Glass et al. in 1978 [2]. The ferroelectric phase transition temperature $(T c=1383 \mathrm{~K})$ was determined by differential thermal analysis and dielectric studies. The spontaneous polarization value $\left(P_{S}=68 \mu \mathrm{C} / \mathrm{cm}^{2}\right)$ was calculated using an empirical dependence of $T_{C}$, because high conductivity prevented direct hysteresis measurements [2]. It was claimed that the observations of electrical domains, pyroelectric behavior, and dielectric and thermal evidence of a phase transition "leave little doubt that this material is correctly classified as ferroelectric" [2]. As-grown domain structure, revealed by etching, represented the shapeless domains up to millimeter size.

The domains at the surface of CVO plates, revealed by etching in a $0.5 \%$ boric acid solution, are usually imaged by optical microscopy $[2,4,5,7]$. Recently, it has been demon- 
strated that confocal Raman microscopy (CRM) [8] and piezoelectric force microscopy (PFM) [9] could be used for detail analysis of as-grown domain structure in CVO [10]. Nevertheless, domain structure in the bulk of CVO single crystals is still unstudied.

In this paper, we present the results of an experimental study of as-grown domain structure in CVO by several methods of domain imaging: optical microscopy, PFM, and Cherenkov-type second harmonic generation (CSHG) [11,12]. The combination of imaging methods provided a unique opportunity for the comprehensive study of domain structure in the bulk, and allowed the revelation of the domain switching during cooling, under the action of the pyroelectric field.

\section{Materials and Methods}

The studied nominally pure CVO single crystals, and those doped with Mn ions (at $0.05 \%$ and $0.1 \%$ ), were grown from the melt, in air, by the Czochralski method with pulling in [100] directions [7]. The grown crystals were about $12 \mathrm{~mm}$ in diameter and up to $45 \mathrm{~mm}$ in length. Then, $0.6-\mathrm{mm}$-thick plates were cut perpendicular to the polar axis. A final surface treatment was done by mechanochemical polishing, using a PM5 machine (Logitech Ltd., Glasgow, UK) with $50 \mathrm{~nm}$ colloidal silica suspension (Allied High Tech Products, Inc., Compton, CA, USA). The polishing procedure revealed a shallow relief corresponding to the surface domain pattern, with a step height of about $100 \mathrm{~nm}$, which was enough for obtaining optical contrast.

Both polar surfaces of the sample were studied by optical microscopy and PFM. Various imaging optical modes (transmitted and reflected light, phase contrast, and bright and dark fields) were realized by means of an optical microscope BX-61 (Olympus, Tokyo, Japan). PFM imaging was performed using an NTEGRA Aura scanning probe microscope (NT-MDT, Moscow, Russia) with silicon NSC-16 tips (MikroMasch, Sofia, Bulgaria), conductive platinum coating, and a typical curvature radius about $25 \mathrm{~nm}$. AC modulation voltage with amplitude $U_{\text {mod }}=10 \mathrm{~V}$ and frequency $f_{\text {mod }}=20 \mathrm{kHz}$ was applied between the tip and the silver-paste solid-bottom electrode. The obtained contrast of piezoelectric response proved that the optical images correspond to ferroelectric domains on the polar surface (Figure 1).


Figure 1. Images of an isolated domain on the polar surface of a nominally pure CVO single crystal: (a) PFM, (b) optical microscopy.

Application of CSHG allowed us to obtain a set of 2D domain images at different depths, with spatial resolution of about $500 \mathrm{~nm}$. This method was realized by means of a homemade setup based on an NTEGRA Spectra scanning probe microscope (NT-MDT SI, Moscow, Russia) with a Yb fiber laser $(1064 \mathrm{~nm}, 40 \mathrm{~mW})$. Treatment of the obtained data by the Blender 3D computer graphics software toolset allowed the construction of 3D domain images. 


\section{Results}

\subsection{Surface Domain Structure}

As-grown domain structure, imaged on the polar surface of all the studied samples by optical microscopy, mostly consisted of rounded shapeless domains (Figure 2). Bright-field transmitted-light optical microscopy allowed imaging of the domain walls on both polar surfaces simultaneously (Figure 2a). The significant difference in the domain wall positions on the opposite polar surfaces proved the existence of charged domain walls in the bulk. Moreover, rounded isolated domains, with diameter below the sample thickness, reached, typically, only one surface, which indicated the absence of essential domain elongation in the polar direction. The typical domain size on the surface ranged from $50 \mu \mathrm{m}$ to $1 \mathrm{~mm}$.
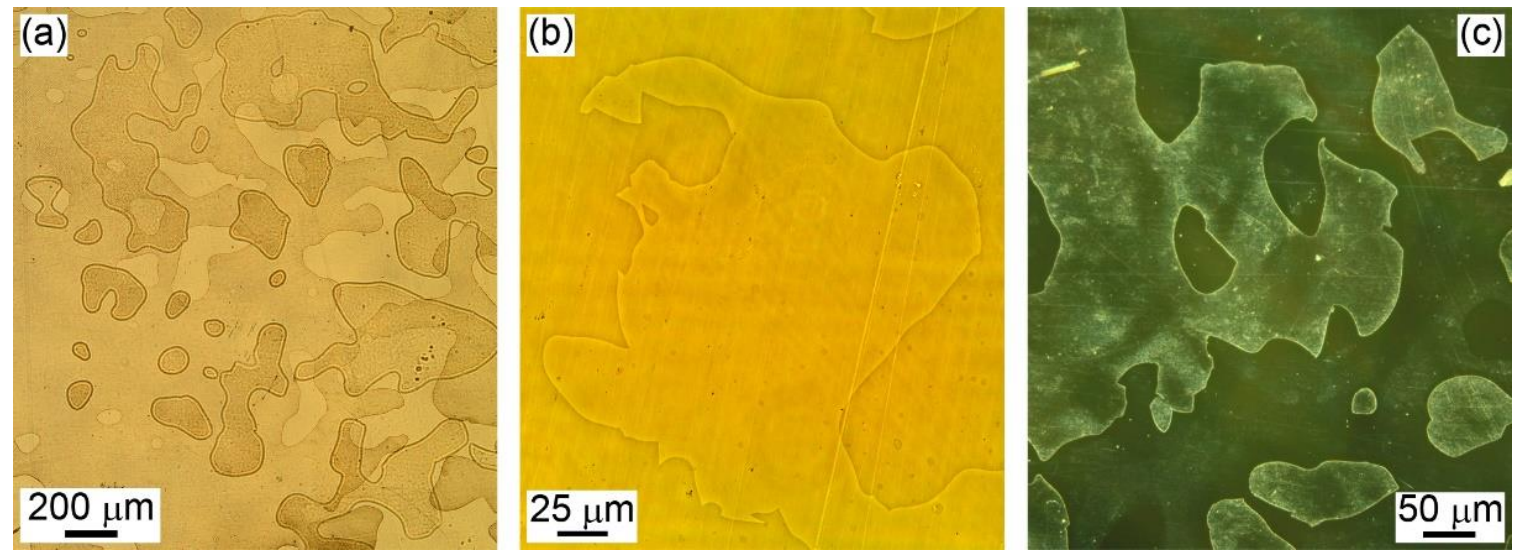

Figure 2. Optical images of as-grown domain structure in (a) nominally pure, (b) $0.05 \%$ Mn-doped, and (c) $0.1 \%$ Mn-doped CVO single crystals. Transmitted light: (a) bright field, (b) phase contrast, (c) dark field.

\subsection{Bulk Domain Structure}

Complete information about domain shape in the bulk was obtained by CSHG. The 3D images of domains in CVO crystals were more complicated than those of domains formed during polarization reversal in lithium niobate (LN) and lithium tantalate (LT) crystals, which typically demonstrate a small tilt of the domain walls from the polar direction $[13,14]$. The domain wall images in the bulk of CVO crystals represent interferometric patterns (Figure 3), which, according to Kampfe et al. [15], correspond to abnormally tilted charged domain walls.
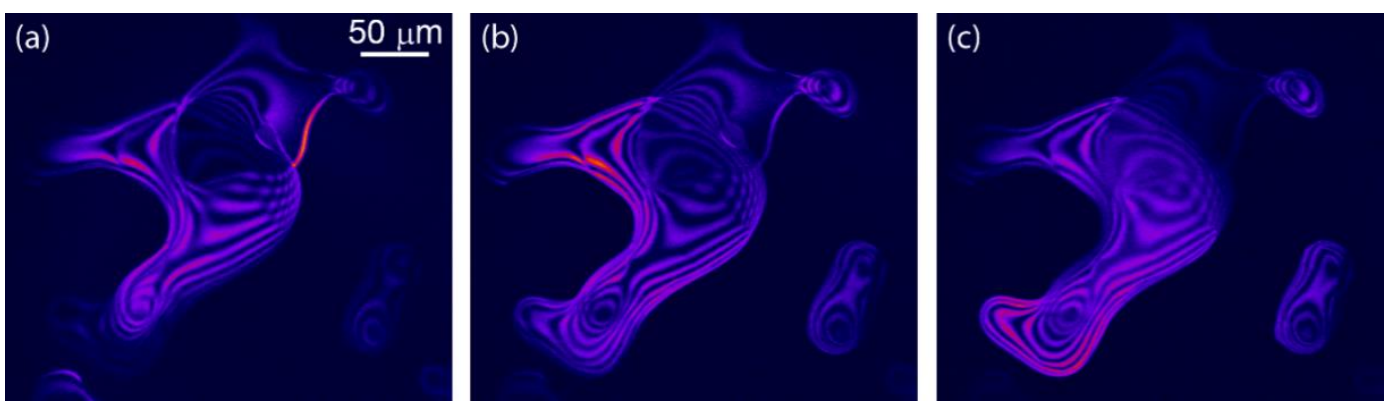

Figure 3. XY scans of as-grown domain structure in nominally pure CVO single crystal, obtained by CSHG, at different focal depths: (a) $78 \mu \mathrm{m}$, (b) $104 \mu \mathrm{m}$, (c) $143 \mu \mathrm{m}$.

We used CSHG to image as-grown domains in the bulk of CVO crystals by recording $\mathrm{XY}$ scans at different focal depths with $13 \mu \mathrm{m}$ steps (Figure 3). According to [15], every bright line in the images represents a cross-section of the domain wall at different depths. The axial displacement between cross sections was equal to $5.8 \mu \mathrm{m}$, for the used fundamental wavelength $(\lambda=1064 \mathrm{~nm})$. The depth of independent cross sections, recorded in a single $X Y$ scan, was defined by numerical aperture of the used objective. The local topology 
of the domain wall was calculated from the obtained $X Y$ scans. 3D reconstruction of the domain structure from Figure 3 was obtained by deconvolution (Figure 4) (see the rotated image in Video S1 in Supplementary Materials).
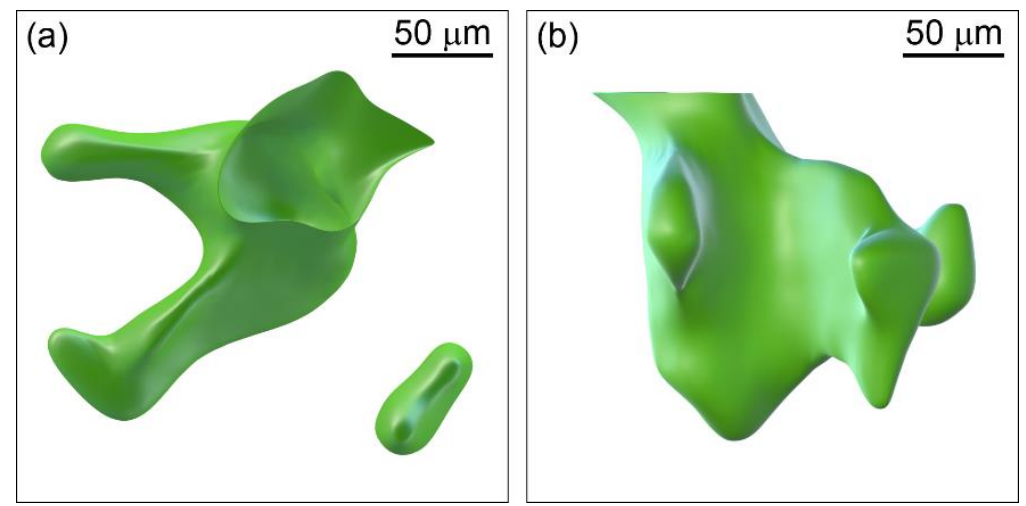

Figure 4. 3D reconstruction of as-grown domains in the vicinity of the polar surface in nominally pure CVO, obtained from the data presented in Figure 4. (a) Top view, (b) side view. Video S1, Supplementary Materials.

Analysis of domain wall position in the bulk allowed us to observe that the domain wall tilt from the polar direction ranged from $11.2^{\circ}$ to $71.4^{\circ}$, with an average value of about $35^{\circ}$.

It was demonstrated that as-grown domain structure in CVO crystals represented a 3D maze, with randomly oriented charged domain walls, strongly tilted from the polar direction. According to bulk imaging, isolated rounded domains rarely occurred. This fact indicates that optical images of rounded domains, observed on the polar surfaces, usually correspond to cross-sections of a large irregular domain maze.

The optically observed as-grown domain structure in both Mn-doped CVO crystals (Figure $2 b, c$ ) looked similar to that of nominally pure ones (Figure 2a). However, the essential difference between the shapes of isolated domains and domain walls of these crystals was revealed. In nominally pure CVO, all domains were rounded (Figure 2a), whereas in $0.05 \%$ Mn-doped (Figure 5a-c) and $0.1 \%$ Mn-doped CVO (Figure 5d), single crystals sometimes showed triangular isolated domains and oriented flat fragments of domain walls, appearing together with rounded domains.
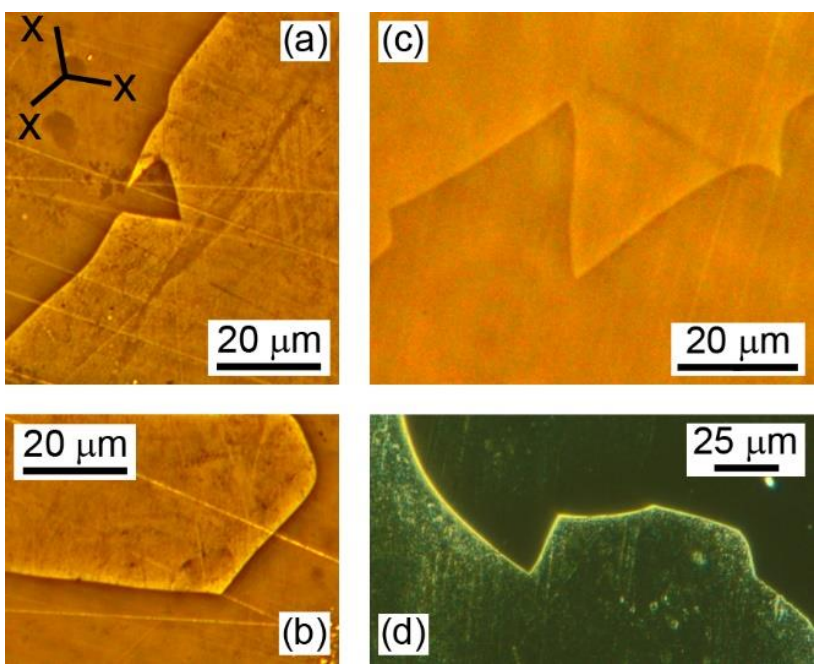

Figure 5. Optical images of as-grown domain structure in (a-c) $0.05 \%$ Mn-doped and (d) $0.1 \%$ Mn-doped CVO single crystals. Transmitted light: (a-c) bright field, (d) dark field. 


\section{Discussion}

The obtained results can be discussed in terms of kinetic approach [16] to formation of as-grown domain structure during phase transition and subsequent cooling [17]. The geometry of the domain structure, formed during slow cooling just below $T_{C}$, is determined by spatial distribution of the internal field, produced by bulk defects and composition inhomogeneities. The obtained absence of the quasi-regular layered domain structure justifies random spatial distribution of the defects, without pronounced growth striations [18-23]. Formation of charged domain walls is caused by low value of the depolarization field and high bulk conductivity, near $T_{C}$. The fast bulk screening of the depolarization field at high temperature stabilizes the formed domain pattern and provides its permanence during slow cooling [17].

During fast cooling to the room temperature, the domain structure can change under the action of the pyroelectric field $[17,24,25]$, for implementation of the following relation:

$$
E_{p y r . z}(T, d T / d t)-E_{t h}(T)>0,
$$

where $E_{p y r . z}(T, d T / d t)$ is the polar component of the pyroelectric field, which depends on temperature and cooling rate, and $E_{t h}(T)$ is the temperature-dependent threshold field for domain switching.

It is important to point out that the shape of the isolated ferroelectric domains that arise during polarization reversal is defined by the crystal's symmetry [26]. A triangular or hexagonal shape in isolated domains is typical for uniaxial ferroelectric crystals of $C_{3}$ symmetry $[21,27,28]$. The formation of flat domain walls is a result of determined step generation and kink motion along the wall [26].

Thereby, it is possible to claim that, in nominally pure CVO crystals, the geometry of the as-grown domain structure, with rounded domains formed near $T_{C}$, persists during subsequent cooling due to effective bulk screening of the depolarization field. The flat oriented fragments of domain walls and triangular domains in Mn-doped CVO appear during switching, under the action of the polar component of the pyroelectric field, above the threshold value. This fact represents the first observation of the domain switching in CVO crystals.

\section{Conclusions}

The domain structure formed after crystal growth in the paraelectric phase and cooling to room temperature, through the ferroelectric phase transition, was studied experimentally in nominally pure and Mn-doped calcium orthovanadate (CVO) crystals. Several methods were used for domain imaging: at the surface-optical microscopy and piezoelectric force microscopy, and in the bulk-Cherenkov-type second harmonic generation. Formation of an irregular 3D maze of rounded domains with charged walls, essentially tilted from the polar direction, was revealed in nominally pure and Mn-doped CVO crystals. The geometry of the domain structure formed during slow cooling, just below $T_{C}$, is determined by spatial distribution of the internal field produced by bulk defects and composition inhomogeneities. The obtained absence of the quasi-regular layered domain structure justifies random spatial distribution of defects, without pronounced growth striations. The persistence of the domain structure with charged walls during cooling can be attributed to effective bulk screening of the depolarization field, and low value of the pyroelectric field. The rare formation of triangular domains and flat fragments of domain walls revealed in Mn-doped CVO was attributed to the action of the excess polar component of the pyroelectric field, above the threshold value for domain switching. This fact represents the first observation of domain switching in CVO crystals. Therefore, we plan to study domain switching in pure and Mn-doped CVO crystals under the action of the pyroelectric field, which arises during heating and cooling with controlled rates.

Supplementary Materials: The following are available online at https:/ /www.mdpi.com/article/10.3 390/cryst11121508/s1, Video S1: rotating 3D image of as-grown domains. 
Author Contributions: Conceptualization, V.S. and E.S.; methodology, E.S.; software, E.L.; investigation, M.N., V.Y. and E.S.; resources, L.I.; writing-original draft preparation, E.S. and V.S.; writing-review and editing, V.S. and E.P.; visualization, M.N., V.Y. and E.S.; supervision, V.S.; project administration, V.S. All authors have read and agreed to the published version of the manuscript.

Funding: This research was funded by the Russian Foundation for Basic Research, grant number 20-02-00588-a, and the Ministry of Science and Higher Education of the Russian Federation, grant numbers 075-15-2021-677 and FEUZ-2020-0054.

Data Availability Statement: The data presented in this study are available on request from the corresponding author.

Acknowledgments: The equipment of the Ural Center for Shared Use "Modern nanotechnology" Ural Federal University (registration number 2968) was used.

Conflicts of Interest: The authors declare no conflict of interest.

\section{References}

1. Brixner, L.H.; Flournoy, P.A. Calcium orthovanadate $\mathrm{Ca}_{3}\left(\mathrm{VO}_{4}\right)_{2}-\mathrm{A}$ new laser host crystal. J. Electrochem. Soc. 1965, 112, 303-308. [CrossRef]

2. Glass, A.M.; Abrahams, S.C.; Ballman, A.A.; Loiacono, G. Calcium orthovanadate, $\mathrm{Ca}_{3}\left(\mathrm{VO}_{4}\right)_{2}-\mathrm{A}$ new high-temperature ferroelectric. Ferroelectrics 1978, 17, 579-582. [CrossRef]

3. Bechthold, P.S.; Liebertz, J.; Deserno, U. Linear and nonlinear optical properties of $\mathrm{Ca}_{3}\left(\mathrm{VO}_{4}\right)_{2}$. Opt. Commun. 1978, 27, 393-398. [CrossRef]

4. Ivleva, L.I.; Dunaeva, E.E.; Voronina, I.S.; Doroshenko, M.E.; Papashvili, A.G. $\mathrm{Ca}_{3}\left(\mathrm{VO}_{4}\right)_{2}: \mathrm{Tm}^{3+}$-A new crystalline medium for 2- $\mu$ m lasers. J. Cryst. Growth 2018, 501, 18-21. [CrossRef]

5. Ivleva, L.I.; Dunaeva, E.E.; Voronina, I.S.; Doroshenko, M.E.; Papashvili, A.G.; Sulc, J.; Kratochvíl, J.; Jelinkova, H. Impact of $\mathrm{Tm}^{3+} / \mathrm{Ho}^{3+}$ co-doping on spectroscopic and laser properties of $\mathrm{Ca}_{3}\left(\mathrm{VO}_{4}\right)_{2}$ single crystal. J. Cryst. Growth 2019, 513, 10-14. [CrossRef]

6. Doroshenko, M.E.; Papashvili, A.G.; Voronina, I.S.; Ivleva, L.I.; Sulc, J.; Kratochvíl, J.; Jelinkova, H. Spectroscopic and laser properties of $\mathrm{Tm}^{3+}$ ions in $\mathrm{Ca}_{3}\left(\mathrm{VO}_{4}\right)_{2}$ crystal. J. Lumin. 2019, 205, 482-486. [CrossRef]

7. Voronina, I.S.; Voronov, V.V.; Dunaeva, E.E.; Iskhakova, L.D.; Papashvili, A.G.; Doroshenko, M.E.; Ivleva, L.I. Growth and properties of manganese doped $\mathrm{Ca}_{3}\left(\mathrm{VO}_{4}\right)_{2}$ single crystals. J. Cryst. Growth 2021, 555, 125965. [CrossRef]

8. Zelenovskiy, P.S.; Fontana, M.D.; Shur, V.Y.; Bourson, P.; Kuznetsov, D.K. Raman visualization of micro- and nanoscale domain structures in lithium niobate. Appl. Phys. A 2010, 99, 741-744. [CrossRef]

9. Shur, V.Y.; Zelenovskiy, P.S. Micro- and nanodomain imaging in uniaxial ferroelectrics: Joint application of optical, confocal Raman and piezoelectric force microscopy. J. Appl. Phys. 2014, 116, 066802. [CrossRef]

10. Shishkina, E.V.; Greshnyakov, E.D.; Zelenovskiy, P.S.; Yuzhakov, V.V.; Ivleva, L.I.; Shur, V.Y. Micro-Raman Domain Imaging in Calcium Orthovanadate Single Crystals. Ferroelectrics 2021, 576, 85-93. [CrossRef]

11. Sheng, Y.; Best, A.; Butt, H.J.; Krolikowski, W.; Arie, A.; Koynov, K. Three-dimensional ferroelectric domain visualization by Čerenkov-type second harmonic generation. Opt. Express 2010, 18, 16539. [CrossRef] [PubMed]

12. Kämpfe, T.; Reichenbach, P.; Schroder, M.; Haußmann, A.; Eng, L.M.; Woike, T.; Soergel, E. Optical three-dimensional profiling of charged domain walls in ferroelectrics by Cherenkov second-harmonic generation. Phys. Rev. B 2014, 89, 035314. [CrossRef]

13. Esin, A.; Akhmatkhanov, A.; Shur, V. Tilt control of the charged domain walls in lithium niobate. Appl. Phys. Lett. 2019, 114, 092901. [CrossRef]

14. Kirbus, B.; Godau, C.; Wehmeier, L.; Beccard, H.; Beyreuther, E.; Haußmann, A.; Eng, L.M. Real-time 3D imaging of nanoscale ferroelectric domain wall dynamics in lithium niobate single crystals under electric stimuli: Implications for domain-wall-based nanoelectronic devices. ACS Appl. Nano Mater. 2019, 2, 5787-5794. [CrossRef]

15. Kämpfe, T.; Reichenbach, P.; Haußmann, A.; Woike, T.; Soergel, E.; Eng, L.M. Real-time three-dimensional profiling of ferroelectric domain walls. Appl. Phys. Lett. 2015, 107, 152905. [CrossRef]

16. Shur, V.Y. Kinetics of ferroelectric domains: Application of general approach to $\mathrm{LiNbO}_{3}$ and LiTaO 3 . J. Mater. Sci. 2006, 41, 199-210. [CrossRef]

17. Shur, V.Y.; Rumyantsev, E.L. Arising and evolution of the domain structure in ferroelectrics. J. Korean Phys. Soc. 1998, 32, S727-S732.

18. Ming, N.-B.; Hong, J.-F.; Feng, D. The growth striations and ferroelectric domain structures in Czochralski-grown LiNbO 3 single crystals. J. Mater. Sci. 1982, 17, 1663-1670. [CrossRef]

19. Chen, J.; Zhou, Q.; Hong, J.F.; Wang, W.S.; Ming, N.B.; Feng, D.; Fang, C.G. Influence of growth striations on para-ferroelectric phase transitions: Mechanism of the formation of periodic laminar domains in $\mathrm{LiNbO}_{3}$ and $\mathrm{LiTaO}_{3}$. J. Appl. Phys. 1989, 66, 336-341. [CrossRef]

20. Evlanova, N.F.; Naumova, I.I.; Chaplina, T.O.; Blokhin, S.A.; Lavrishchev, S.V. Periodically poled Y:LiNbO $\mathrm{L}_{3}$ single crystal: Impurity distribution and domain wall location. J. Cryst. Growth 2001, 223, 156-160. [CrossRef] 
21. Shur, V.Y.; Gruverman, A.L.; Letuchev, V.V.; Rumyantsev, E.L.; Subbotin, A.L. Domain structure of lead germanate. Ferroelectrics 1989, 98, 29-49. [CrossRef]

22. Blistanov, A.A.; Antipov, V.V.; Kugaenko, O.M.; Mikhailova, G.S. Effect of inhomogeneity on the formation of regular domain structures in $\mathrm{LiNbO}_{3}$ crystal. Crystallogr. Rep. 2002, 47, 111-116. [CrossRef]

23. Bermúdez, V.; Caccavale, F.; Diéguez, E. Domain walls characterization of the opposite domain lithium niobate structures. J. Cryst. Growth 2000, 219, 413-418. [CrossRef]

24. Shur, V.Y.; Kuznetsov, D.K.; Mingaliev, E.A.; Yakunina, E.M.; Lobov, A.I.; Ievlev, A.V. In situ investigation of formation of self-assembled nanodomain structure in lithium niobate after pulse laser irradiation. Appl. Phys. Lett. 2011, 99, 082901. [CrossRef]

25. Shur, V.Y.; Kosobokov, M.S.; Makaev, A.V.; Kuznetsov, D.K.; Nebogatikov, M.S.; Chezganov, D.S.; Mingaliev, E.A. Dimensionality increase of ferroelectric domain shape by pulse laser irradiation. Acta Mater. 2021, 219, 117270. [CrossRef]

26. Shur, V.Y.; Pelegova, E.V.; Kosobokov, M.S. Domain shapes in bulk uniaxial ferroelectrics. Ferroelectrics 2020, 569, 251-265. [CrossRef]

27. Lobov, A.I.; Shur, V.Y.; Baturin, I.S.; Shishkin, E.I.; Kuznetsov, D.K.; Shur, A.G.; Dolbilov, M.A.; Gallo, K. Field induced evolution of regular and random 2D domain structures and shape of isolated domains in $\mathrm{LiNbO}_{3}$ and $\mathrm{LiTaO}_{3}$. Ferroelectrics 2006, 341, 109-116. [CrossRef]

28. Shur, V.Y.; Nikolaeva, E.V.; Shishkin, E.I.; Chernykh, A.P.; Terabe, K.; Kitamura, K.; Ito, H.; Nakamura, K. Domain shape in congruent and stoichiometric lithium tantalate. Ferroelectrics 2002, 269, 195-200. [CrossRef] 